\title{
Fenomenologia e educação: uma abertura recíproca
}

\section{Phenomenology and education: a reciprocal opening}

\author{
Claudinei Aparecido de Freitas da Silva ${ }^{1}$
}

\begin{abstract}
Resumo
O ensaio busca reconfigurar as interfaces entre a fenomenologia e a prática educativa. Propomos, portanto, interrogar o estatuto que sela a legitimidade de tal debate, seu alcance e possíveis limites sob o horizonte aberto pela obra de Merleau-Ponty.

Palavras-Chave: Fenomenologia. Educação. Corpo. Alteridade.
\end{abstract}

\begin{abstract}
The essay seeks to reconfigure the interfaces between phenomenology and educational practice. It is proposed, therefore, to question the status that seals the legitimacy of such debate, its scope and possible limitations below the horizon opened by the works of Merleau-Ponty.
\end{abstract}

Keywords: Phenomenology. Education. Body. Alterity.

Arelação entre filosofia e educação protagonizam um diálogo que se estende desde a mais remota história do pensamento. A paideia grega é uma amostra original que, ainda, nos tempos atuais, permanece viva na memória daqueles que nunca deixaram de reconhecer o laço profundamente consangüíneo jamais cortado entre esses dois territórios gêmeos do saber. Platão e Aristóteles vivificaram, em suas obras, essa coesão intrínseca, a ponto de observar que a atitude do espanto ou da admiração constitui, de maneira sui generis, o princípio de toda filosofia, e esse princípio era admiravelmente encarnado por Sócrates, no exercício da maiêutica como práxis pedagógica por excelência. Ora, Husserl, o fundador do novo programa filosófico contemporâneo denominado fenomenologia, costumava hastear a bandeira desse ousado projeto a partir de um lema fundamental: "o retorno às coisas mesmas". Qual é, de fato, a radicalidade e o alcance último desse propósito e, em que medida, ele pode ser compreendido como um retorno àquela intenção mais primordial que os gregos vislumbravam no horizonte, digamos assim, de uma autêntica philos pedagógica?

Uma obra que, de maneira inteiramente especial, parece pôr-se a caminho como um guia indispensável nesse percurso é a perspectiva fenomenológica da qual parte Merleau-Ponty. Merleau-Ponty radicaliza ainda mais o projeto fenomenológico husserliano que assumia, ainda, o postulado de um novo idealismo transcendental. Para se repensar filosoficamente uma verdadeira ação pedagógica, é necessário, para além de qualquer forma de racionalismo ou empirismo, trazer à tona o sentido do mundo, do corpo, da percepção, da linguagem, do outro. É impossível tratar esses temas concêntricos servindo-se, ainda, do aparato paradigmático da dicotomia sujeito

\footnotetext{
1 Professor dos Cursos de Graduação e de Pós-Graduação (Mestrado) em Filosofia da UNIOESTE - Campus Toledo. Endereço para contato: Rua da Faculdade, 645 - CEP: 85903.000 - Toledo (PR). E-mail: cafsilva@uol.com.br.
} 
e objeto, embora essa mesma dicotomia tivesse separado a alma do corpo, o eu do outro, a teoria da prática.

Será preciso entrever, aqui, entre a ação e o conhecimento um acordo recíproco, uma dialética mais vital capaz de selar o elo indissolúvel entre ambos. Ora, toda práxis não só pedagógica, mas historiográfica, sociológica, antropológica e até mesmo epistemológica, só se impulsiona sob esse movimento dialético, cujo ímpeto precursor, a ágora grega fora um cenário exemplar de intenso exercício, reflexão e engajamento. A fenomenologia, advoga Merleau-Ponty, é a retomada radical $^{2}$ desse empreendimento na medida em que ela parece cultivar uma nova teoria da aprendizagem. É assim, ao final do prefácio à Phénoménologie de la Perception, que Merleau-Ponty dá vazão à tese de que "a verdadeira filosofia consiste em reaprender a ver o mundo." (MERLEAU-PONTY, 1942, p. xvi). Ora, ao retomar aquele velho lema husserliano, Merleau-Ponty passa a mostrar que "retornar às coisas mesmas é retornar a este mundo anterior ao conhecimento do qual o conhecimento sempre fala" (MERLEAU-PONTY, 1942, p. iii). Fazer filosofia ou fenomenologia está bem longe, acredita ele, de tomar o mundo, a natureza, o outro, as coisas, como um objeto já dado, fechado, completamente elucidado, solucionado. Trata-se, antes, de compreender uma experiência do mundo e da vida que precede a qualquer intervenção científica, ideológica ou até mesmo filosófica. Nisso é que reside a radicalidade da fenomenologia: se ela quiser "permanecer fiel à sua intenção, não saberá aonde vai. $\mathrm{O}$ inabamento da fenomenologia e o seu andar incoativo não são signo de um fracasso - eles eram inevitáveis - porque a fenomenologia tem como tarefa revelar o mistério do mundo e o mistério da razão"(MERLEAU-PONTY, 1945, p. xvi). Nessa perspectiva, "tudo aquilo que sei do mundo, mesmo pela ciência, eu o sei a partir de uma visão minha ou de uma experiência do mundo sem a qual os símbolos da ciência não poderiam dizer nada" (MERLEAU-PONTY, 1945, p. ii ). É preciso compreender que a filosofia é o "conjunto de questões no qual aquele que questiona é ele próprio posto em causa pela questão" (MERLEAU-PONTY, 1964, p. 47). Ora, “o homem está no mundo, é no mundo que ele se conhece" (MERLEAU-PONTY, 1945 , p. v.). O mundo deixa de ser para ele um simples objeto de conhecimento ou uma ideia da razão, para se tornar a experiência mais gratuita, o solo originário, manifesto, em carne e osso, pela percepção. O que é a percepção?

A percepção não é, conforme acreditara Descartes, um ato intelectual, uma operação analítica ou se quiser, uma ciência do mundo. Ela é o "fundo sobre o qual todos os atos se destacam" (MERLEAU-PONTY, 1945, p. v). Assim, observa Merleau-Ponty, pela experiência do corpo próprio "situado aqui e agora" (MERLEAU-PONTY, 1945, p. 47), somos reenviados ao "tufo vivo da percepção” (MERLEAU-PONTY, 1945, p. 48), isto é, nos orientamos em meio ao movimento de uma inteligibilidade operante, seguimos uma lógica vivida, a saber, a percepção mesma em seu evento de origem como uma "iniciação ao mundo" (MERLEAU-PONTY, 1945, p. 297), uma "comunicação ou uma comunhão" (MERLEAUPONTY, 1945, p. 370). Ora, essa comunhão com o mundo, assegurada pela percepção, é o signo de nossa encarnação, ou seja, a situação de fato mais originária desde onde jamais rompemos qualquer vínculo. Trata-se, sobretudo, da experiência de nossa consangüinidade, cujo cordão umbilical jamais cortamos. Este tema nuclear trazido aqui por Merleau-Ponty enseja outras duas ordens de questões que se tornam decisivas não só de um ponto de vista fenomenológico, mas, especialmente, aqui, sob uma perspectiva essencialmente pedagógica. Que questões seriam essas? A questão do corpo e a questão do outro.

2 “Ser radical é apanhar as coisas pela raiz. Ora, para o homem, a raiz é o próprio homem.” (MARX, 2005, p. 151). 
O papel conferido por Merleau-Ponty ao tema do corpo é decisivo. Só podemos falar de consciência ou subjetividade se levarmos em conta que o "sujeito" se revela, antes de tudo, como um "sujeito consagrado ao mundo" (MERLEAU-PONTY, 1945, p. v). Ora, como se opera essa consagração, esse engajamento ou essa "encarnação numa natureza"3?" ? Ela só pode se manifestar numa ordem de experiência radicalmente concreta na qual o sujeito se reconhece enquanto um ser em situação, realizando "sua ipseidade efetivamente como corpo e entrando, através desse corpo, no mundo" (MERLEAU-PONTY, 1945, p. 467). O corpo, nesse contexto fenomenológico, projeta já um alcance pedagógico: ele nos ensina que experiência humana extravasa os limites puramente biológicos, físicos, materiais. Não se trata mais do corpo reduzido como objeto da anatomia ou da fisiologia. Trata-se do corpo como um ser de fenômeno, quer dizer, um comportamento que se revela como princípio de transcendência. Jamais percebemos, por exemplo, a mímica da cólera como "um fato psíquico escondido atrás do gesto, leio a cólera no gesto, o gesto não me faz pensar na cólera, ele é a própria cólera" (MERLEAU-PONTY, 1945, p. 215). "Conhecese melhor o homem por suas condutas do que por seus pensamentos" (MERLEAU-PONTY, 1996, p. 131). Nessa perspectiva, o sentido dos gestos não é dado, mas compreendido; ele se confunde com uma certa estrutura do mundo. É nessa extensão que a experiência da corporeidade anuncia outra genuína experiência como um fenômeno inalienável: a experiência do outro.

Da mesma forma que, na experiência do corpo, o outro não se põe diante de mim como um objeto, ele não é uma coisa, um espectro ou até mesmo um fantasma segundo a célebre caricatura de Descartes na segunda meditação, mas o prolongamento corporal, comportamental de mim mesmo. É carne de minha carne. É meu espelho: vejo-me através do outro. Esse mútuo reconhecimento só é possível porque "nós nada mais somos do que esse laço de relações" (MERLEAU-PONTY, 1945, p. xvi). Somos, ambos, vislumbrados, sob um mesmo horizonte de existência, já que estamos no mundo, mantemos, com o mundo, relações de comércio. Merleau-Ponty mostra que essa percepção, isto é, a aparição do outro num só horizonte, não é uma ficção. Jamais renunciamos a "essa tese do mundo, a esse interesse do mundo que nos define" (MERLEAU-PONTY, 1945, p. ix), porque o corpo de outrem e meu corpo compõe o verso e reverso de um mesmo campo de experiência. Experiência de intimidade, de familiaridade. Há, aí, um só DNA. Uma mesma relação congênita, carnal, intersubjetiva. Claro que Pedro é Pedro e Maria é Maria. Em que pesem suas diferenças, há, por outro lado, uma dimensão mais geral, abrangente que os irmana num só tecido comum, aquilo que Merleau-Ponty chamará de Carne, isto é, "o meio formador do sujeito e do objeto" (MERLEAUPONTY, 1964, p. 193). A carne é "essa massa sensível na qual vivo” (MERLEAU-PONTY, 1942, p. 228), em que "sou arrastado numa coexistência da qual não sou o único constituinte" (MERLEAUPONTY, 1945, p. 239). Assim, se jamais rompemos nossa familiaridade com o mundo, também jamais podemos desconsiderar nossa filiação ou nosso grau de parentesco com o outro. Não há espírito absoluto, eu puro, mas uma consciência que anuncia outra consciência e, isso, graças à coesão carnal que nos une ao mundo e a outrem. Estamos indivisivelmente ligados num só círculo, não um círculo vicioso, mas uma circularidade hermenêutica fundamental de experiência.

\footnotetext{
${ }^{3}$ MERLEAU-PONTY, (1945, p. vii). É significativamente esse horizonte temático que consagramos em nossos dois livros: SILVA, Claudinei Aparecido de Freitas. A carnalidade da reflexão: ipseidade e alteridade em Merleau-Ponty. São Leopoldo, RS: Nova Harmonia, 2009 e SILVA, Claudinei Aparecido de Freitas. A natureza primordial: Merleau-Ponty e o logos do mundo estético. Cascavel, PR: Edunioeste, 2010 (Série Estudos Filosóficos, n 12).
} 
Em seus memoráveis cursos sobre a psicologia e pedagogia da criança ministrados no período de 1949 a 1952 na Sorbonne, Merleau-Ponty ilustra: “A criança reconhece em outrem outro 'ela mesma'. A linguagem é o meio de realizar uma reciprocidade com ele" (MERLEAU-PONTY, 2001, p. 30). Aí, “o eu se ignora como centro do mundo" (MERLEAUPONTY, 2001, p. 35). Temos, aqui, uma ideia essencial: a experiência infantil desconstrói um antigo modelo pedagógico: a própria linguagem da criança já é essa genuína amostra de que o solipsismo é uma posição autofágica, pois há um "mundo único", intersubjetivamente válido. Em suma, temos muito que aprender com a criança. O cruzamento entre a fenomenologia com a educação não pode perder de vista esse estágio pueril que está na raiz de todo saber ou conhecimento.

Por isso, a construção do conhecimento, seja ela qual for, é essencialmente intersubjetiva, coletiva. É perpassada por tudo aquilo que a história lega como herança cultural. $\mathrm{O}$ outro é a expressão mais palpável desse legado. E aí que nossas perspectivas se cruzam, se confrontam, se conjugam a ponto de redefinir o sentido último da própria práxis pedagógica.

Um novo horizonte é aberto. Merleau-Ponty compreende que deve haver uma abertura recíproca entre a ciência e a filosofia. Para além dos limites estreitos de uma racionalidade formalmente restritiva, endógena, trata-se de redefinir outro horizonte do conceito de razão mais abrangente, uma "razão alargada" (MERLEAU-PONTY, 1996, p. 79). Uma racionalidade mais dialógica e que não seja um "pensamento aposentado ou enrugado", mas uma forma de pensamento que "procura fundamentalmente ver" (MERLEAU-PONTY, 1953, p. 45).

Merleau-Ponty quer pensar uma prática filosófica e pedagógica que esteja liberta da cultura do profissionalismo filosófico confinada:

[...] num universo acadêmico onde as opções da vida estão amortecidas e as oportunidades do pensamento veladas [...]. Ora, a filosofia livresca deixou de interrogar os homens. O que nela há de insólito e de quase insuportável está oculto na vida decente dos grandes sistemas. Para reencontrarmos a função integral do filósofo precisamos lembrar-nos de que até os filósofos-autores que lemos, e que somos, nunca deixaram de reconhecer como mestre um homem que não escrevia, que não ensinava - pelo menos nas cátedras do Estado - que se dirigia àqueles que encontrava na rua e que teve dificuldades com a opinião pública e com os poderosos, precisamos lembrar-nos de Sócrates (MERLEAU-PONTY, 1953, p. 39).

Como vemos, a figura de Sócrates, nesse contexto, tem muito a ensinar. Ela metaforiza a utopia de uma racionalidade mais pública, plural e, portanto, menos privada, sectária, ideológica. Uma racionalidade que transita numa relação viva com as coisas, com o mundo e com o outro, encarnandose no acontecimento, transcendendo, a rigor, os muros da academia. Aqui, a educação se alia a uma exigência fenomenológica que Husserl jamais prescindira: "Não é das filosofias que deve partir o impulso da investigação, mas, sim, das coisas e das questões" (HUSSERL, 2003, p. 85). MerleauPonty retoma esse princípio, problematizando que o conhecimento não pode ser subjugado por algum método, no sentido de um procedimento canônico, técnico ou algum tratamento puramente estatístico. Menos ainda, por um sistema filosófico. Antes de qualquer adoção metodológica, é preciso primeiro reapreender, isto é, ver desinteressadamente, experienciar um contato ingênuo com o mundo em seu estado nascente, primordial. Por isso, quando se problematiza a aplicação de um método fenomenológico em qualquer prática científica, estamos antes diante de "uma postura de ação assumida pelo pesquisador do que da adesão a um referencial teórico" (MARTINS; KENIAN, 1984, p. 75). "A fenomenologia", avalia Merleau-Ponty 
(1945, p. ii), "se deixa praticar e reconhecer como maneira ou como estilo; ela existe como movimento antes de ter chegado a uma inteira consciência filosófica [...]. É preciso ligar os famosos temas fenomenológicos assim como eles se ligaram espontaneamente na vida [...]. Trata-se de descrever,

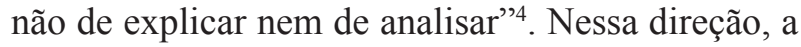
práxis fenomenológica se confunde com a própria práxis educativa: ela é, a bem da verdade, "animada por uma forma de experiência que não é imediatista, não prevê resultados, não apresenta soluções, não forma discípulos, nem tampouco pretende ser soteriológica"(SILVA, 2007, p. 46). "Essa não é mais a experiência de laboratório, é a experimentada da vida" (MERLEAU-PONTY, 1996, p. 82). Para usar uma bela fórmula que Iraquitan Caminha moldura em seu livro O Distante-Próximo e o PróximoDistante, trata-se, aqui, de uma "fenomenologia da experiência de ver" (CAMINHA, 2010a, p. 125), uma vez que "ver", ilustra ele, "é já ser presente no mundo" (CAMINHA, 2010a, p. 337). Ora, nos lembra, aqui, o professor Caminha em sua conferência, "a fenomenologia pode nos ensinar que educar exige um engajamento de cuidar do outro [...]. Ela revela a nossa condição de sermos artesãos de formas de vida" (CAMINHA, 2010b, p. 3-4).

Essa parece ser também a perspectiva que se move Heidegger, um dos pensadores mais marcantes da tradição fenomenológica e que fora aluno de Husserl. Em tese, avalia ele:

É bem sabido que ensinar é ainda mais difícil que aprender. Mas raramente se pensa nisso. Por que ensinar é mais difícil que aprender? Não porque o mestre deva possuir um maior acervo de conhecimentos e os ter sempre à disposição. Ensinar é mais difícil do que aprender, porque ensinar quer dizer 'deixar aprender'. Aquele que verdadeiramente ensina não faz aprender nenhuma outra coisa que não seja o aprender. É por isso que o seu fazer causa muitas vezes a impressão que junto dele nada se aprende. Isso acontece porque inconsideradamente entendemos por 'aprender' a só aquisição de conhecimentos utilizáveis. $\mathrm{O}$ mestre que ensina ultrapassa os alunos que aprendem somente nisto: que ele deve aprender ainda muito mais do que eles, porque deve aprender a 'deixar aprender'. O mestre deve poder ser mais ensinável que os alunos. O mestre é muito menos seguro de seu ofício que os alunos do seu. Por isso, no relacionamento do mestre que ensina e dos alunos que aprendem, quando o relacionamento for verdadeiro, jamais entram em jogo a autoridade de quem sabe muito bem nem a influência autoritária do representante magisterial. Por causa disso é ainda uma grandeza ser mestre - que é bem outra coisa que ser professor célebre. Se hoje - onde tudo é medido sobre o que é baixo e conforme ao que é baixo, por exemplo, sobre o lucro - ninguém mais deseja ser mestre, isso é devido, sem dúvida, ao que esta grande 'coisa' implica e à grandeza de si própria (HEIDEGGER, 1973, 89).

Essa observação, a propósito da natureza da experiência didática, parece cair como uma luva. Heidegger parece oferecer-nos aqui, em primeira mão, muito mais que um mero roteiro retórico, o relato de uma experiência, sem dúvida alguma, árdua e paciente acerca da natureza do "ensinar" e do "aprender". Tudo se passa como se o ensino propriamente dito, mais que uma mera transmissão de conteúdos, se revelasse como uma arte; arte no sentido de um ouvir permanente, uma incansável percepção do outro, do corpo, do mundo; em suma, do comportamento autenticamente pedagógico, cujo cenário privilegiado, todos os personagens envolvidos (mestre e aluno) contracenam um só enredo. Nessa íntima relação, o que se estabelece

\footnotetext{
${ }^{4}$ MERLEAU-PONTY (1945, p. ii) Conforme Lévinas, a fenomenologia como filosofia "não chegou a ser uma ciência rigorosa, prosseguida por uma equipe de investigadores que culmina em resultados definitivos. Muito provavelmente, a filosofia recusa esse modo de vida espiritual, embora algumas das esperanças husserlianas se realizaram. A fenomenologia une os filósofos, sem que isto ocorra da maneira em que o kantismo unia os kantianos ou o espinosismo, os espinosistas. Os fenomenólogos não aderem às teses formalmente enunciadas por Husserl; não se consagram exclusivamente à exegese ou à história de seus escritos. O que os aproxima é uma maneira de trabalhar. Eles se unem para abordar os problemas de uma determinada maneira ao invés de aderir a certo número de proposições fixas [...]. A fenomenologia é método de uma maneira eminente, pois ela está essencialmente aberta [...]. Nesse ponto, a obra de Husserl não parece haver atuado pelas suas considerações metodológicas. Por outro lado, na maioria das vezes, elas expressam muito mais posições e respostas a problemas, que regras sobre a arte de tratálas" (apud LÉVINAS, 1968, p. 88).
} 
é um intenso diálogo com a realidade, o verdadeiro retorno às coisas mesmas, permeado, é claro, por um espírito de disciplina e devoção à tarefa mesma do pensamento. Trata-se de uma "pedagogia sem pressupostos iniciais” (MACHADO, 2010, p. 14), uma experiência que fale do mundo em carne e osso. Nesse contexto, a figura do educador e do educando se desconstrói radicalmente: para além de toda relação formal, asfixiante, transcendemos qualquer polarização pedagógica, já que, em tal modelo de proposta, não se trata de simplesmente, como lembrara antes Heidegger, de transmitir conteúdos, menos ainda, formar discípulos. $\mathrm{O}$ educando também deve tomar as rédeas da autêntica práxis pedagógica, num espírito de livre investigação. Ele deve aprender a "caminhar com as próprias pernas", isto é, construir seu próprio percurso investigativo, visando sempre, sua emancipação intelectual. Ora, mas, para que essa difícil conquista venha lograr algum êxito, será preciso, como exortava Heidegger, que o mestre reconheça que ele necessita "aprender ainda muito mais do que o aluno, justamente porque deve aprender a 'deixar aprender'”. Só assim, acreditamos que não só a filosofia em especial, mas qualquer outra área ou disciplina do conhecimento deve ser um acontecimento sempre criativo, liberto de todo engessamento burocrático-acadêmico, meramente funcional.

É sob essa perspectiva que a fenomenologia parece sugerir elementos para uma reflexão mais efetiva, profundamente engajada, de toda práxis educacional. Ela explora a ideia de que teoria e prática são inseparáveis; são duas faces de uma mesma moeda de troca, cujo valor é inesgotável no mercado do capitalismo acadêmico.

\section{Referências}

CAMINHA, I. O. O distante-próximo e o próximodistante: corpo e percepção na filosofia de MerleauPonty. João Pessoa: Editora Universitária da UFPB, 2010a.

Fenomenologia e educação. In: SEMANA DA

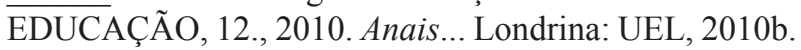

HUSSERL, E. La philosophie comme science rigoureuse. 4. ed. Paris: PUF, 2003.

LÉVINAS, E. Reflexiones sobre la 'técnica' fenomenológica. In: GUILLERMO, A. Maci. Husserl: cahiers de tercer coloquio de Royaumont. Buenos Aires: Paidós, 1968.

MACHADO, M. M. Merleau-Ponty \& a educação. Belo Horizonte: Autêntica Editora, 2010. (Coleção Pensadores \& Educação, 19).

MARTINS, J.; KENIAN, M. F. Temas fundamentais de fenomenologia. São Paulo: Moraes, 1984.

MARX, K.. Crítica da filosofia do direito de Hegel: Introdução. In: _. Crítica da filosofia do direito de Hegel. Tradução de Rubens Enderle e Leonardo de Deus. São Paulo: Boitempo, 2005, p. 145-156.

MERLEAU-PONTY, M. La structure du comportement. Paris: PUF, 1942.

. Phénoménologie de la perception. Paris: Gallimard, 1945.

. Éloge de la philosophie et autres essais. Paris: Gallimard, 1953. . Le visible et l'invisible. Paris: Gallimard, 1964. . Sens et non-sens. Paris: Gallimard, 1996.

Psychologie et pédagogie de l'enfant: cours de sorbonne (1949-1952). Paris: Verdier, 2001.

SILVA, C. A. F. A carnalidade da reflexão: ipseidade e alteridade em Merleau-Ponty. São Leopoldo: Nova Harmonia, 2009.

. A natureza primordial: Merleau-Ponty e o logos do mundo estético. Cascavel: Edunioeste, 2010 (Série Estudos Filosóficos, 12).

O "retorno" da "coruja". Tempo da Ciência,

Toledo, v. 14, n. 28, p. 45-57, 2007. 